\title{
The surface albedo of the Greenland ice sheet: satellite- derived and in situ measurements in the Søndre Strømfjord area during the 1991 melt season
}

\author{
Wouter H. Knap and Johannes Oerlemans \\ Institute for Marine and Atmospheric Research Utrecht, University of Utrecht, Princelonplein 5, 3584 CC Utrecht, The Netherlands
}

\begin{abstract}
The temporal and spatial variation in the surface albedo of the Greenland ice sheet during the ablation season of 1991 is investigated. The study focuses on an area east of Sondre Strømfjord measuring $200 \mathrm{~km}$ by $200 \mathrm{~km}$ and centred at $67^{\circ} 5^{\prime} \mathrm{N}, 48^{\circ} 13^{\prime} \mathrm{W}$. The analysis is based on satellite radiance measurements carried out by the Advanced Very High Resolution Radiometer (AVHRR). The broad-band albedo is estimated from the albedos in channel 1 (visible) and channel 2 (nearinfrared). The results are calibrated with the surface albedo of sea and dry snow.

Satellite-derived albedos are compared with GIMEX ground measurements at three stations. There is a high degree of consistency in temporal variation at two of the three stations. Large systematic differences are attributed to albedo variations on subpixel scale.

In the course of the ablation season four zones appear, each parallel to the ice edge. It is proposed that these are, in order of increasing altitude: (I) clean and dry ice, (II) ice with surface water, (III) superimposed ice, and (IV) snow. An extensive description of these zones is given on the basis of the situation on 25 July 1991. Zones I, III and IV reveal fairly constant albedos $(0.46,0.65$ and 0.75 on average), whereas zone II is characterised by an albedo minimum $(0.34)$. Survey of the western margin of the Greenland ice sheet (up to $71^{\circ} \mathrm{N}$ ) shows that the zonation occurs between $66^{\circ}$ and $70^{\circ} \mathrm{N}$.
\end{abstract}

\section{INTRODUGTION}

The ice volume of the Greenland ice sheet, the second largest ice sheet on Earth, is estimated to be $3 \times 10^{6} \mathrm{~km}^{3}$. Complete melting of this volume would raise the global mean sea level by about $7 \mathrm{~m}$ (Warrick and Oerlemans, 1990). As the ice sheet is situated in a relatively warm climate, it is sensitive to climatic change. Recent concern about enhanced greenhouse warming and possible sea-level rise points to the importance of model studies which attempt to quantify the response of the Greenland ice sheet to climatic change. The mass balance of the ice sheet is to a large extent determined by the summer energy balance (e.g. Ambach, 1963). Model studies that are based on the explicit treatment of energy exchange between the atmosphere and the glacier surface should therefore start with a calculation of the surface energy balance. Such studies have been carried out by, for example, Greuell (1992) for the Swiss ETH camp in West Greenland and van de Wal and Oerlemans (1994) for the entire Greenland ice sheet. Since most energy for melting is supplied by solar radiation, the albedo is the key quantity in simulations of the mass balance. In order to develop realistic albedo parameterizations, one needs to understand the complex variations of the albedo in space and time. Satellite data provide an excellent opportunity to study these variations on both a global and a regional scale.
The present paper describes the spatial and temporal variation in the surface albedo of the central western part of the Greenland ice sheet, east of Søndre Stromfjord (Kangerlussuaq). The study region is centred at about $67^{\circ} 5^{\prime} \mathrm{N}, 48^{\circ} 13^{\prime} \mathrm{W}$ and covers an area of $200 \mathrm{~km}$ by $200 \mathrm{~km}$ (Fig. 1). It extends from about $150 \mathrm{~m}$ a.s.l. at the ice edge to about $2100 \mathrm{~m}$ a.s.l. at the eastern boundary. During the early 1990s, the mean equilibrium-line altitude (ELA) lay at about $1400 \mathrm{~m}$ a.s.l. (van de $\mathrm{Wal}$ and others, in press), and therefore a significant part of the area consisted of ice during the ablation season. Basically, we selected this area so that we could study the remarkable behaviour of the albedo which came to light during the Greenland Ice Margin Experiment (GIMEX) of 1991 (Oerlemans and Vugts, 1993). In contrast to the situation on mountain glaciers, lowest values of the albedo were not found near the ice edge, but higher on the ice sheet. So that we could study this feature as well as the development of the albedo on a larger scale throughout the ablation season of 1991, several NOAA AVHRR (Advanced Very High Resolution Radiometer) images were processed and studied. The retrieval method will be described in section 2. A comparison between satellite-derived and in situ albedos during GIMEX, together with an analysis of the differences found, will be presented in section 3 . The evolution of the albedo on larger scale and a division in glacier zones will be discussed in section 4 . 


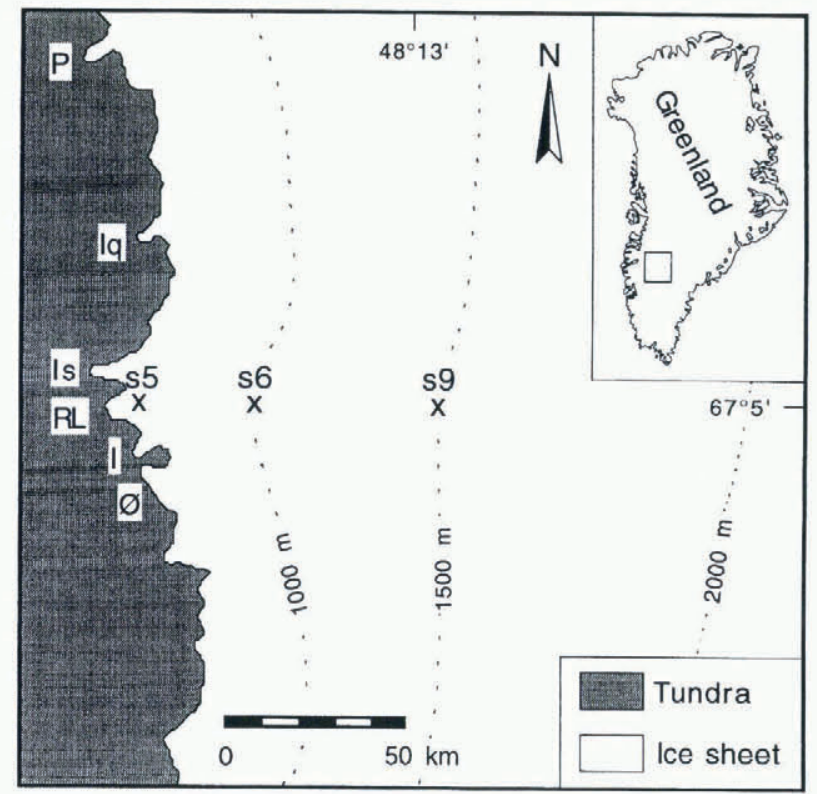

Fig. 1. Map of the study area. The crosses indicate GIMEX sites 5, 6 and 9 (at 519, 1028 and $1520 \mathrm{~m}$ a.s.l.). Names of some outlel glaciers are included: P, Polonia Gletscher or Usugdlûp sermia; Iq, Inugpait qûat; Is, Isúnguata sermia; RL, Russell and Leverell Glaciers; I, Isorlersuup Gletscher; and O, Orkendal Gletscher (Scholz and Grottenthaler, 1988; Weidick and others, 1992).

\section{METHOD}

The surface albedo was derived from radiance $\left(\mathrm{W} \mathrm{m}^{-2} \mathrm{sr}^{-1}\right)$ measurements carried out by the AVHRR, a sensor on board the NOAA-11 satellite (and successors). This satellite was in orbit from 1988 to 1995 and provided daily coverage of the study area at a nominal altitude of $850 \mathrm{~km}$ above the surface. The AVHRR was designed to measure in five spectral bands of the electromagnetic spectrum, of which band 1 (visible: $560-680 \mathrm{~nm}$ ) and band 2 (near-infrared: $730-1100 \mathrm{~nm}$ ) were used to derive the albedo. The radiometer is a cross-track scanning instrument with a ground resolution ranging from $1.1 \mathrm{~km}$ at nadir to $2.4 \mathrm{~km}$ (along track) or $6.9 \mathrm{~km}$ (across track) at the swath edge $\left(55.4^{\circ}\right.$ off-nadir). The reader is referred to Lauritson and others (1979) for further technical details about the instrument.

The following expression relates the AVHRR count level $(C)$ to the so-called effective albedo at satellite level $\left(A_{i}\right)$ (Abel, 1990):

$$
A_{i}=S_{i} C+I_{i}
$$

The index $i$ refers to the AVHRR spectral band $(i=1,2)$. An effective albedo of $100 \%$ corresponds to the radiance received from a perfectly Lambertian surface illuminated by the sun at normal incidence at the top of the Earth's atmosphere. The effective albedo was calculated on the basis of pre-launch values of slope and intercept: $S_{1}=0.095, S_{2}=0.090, I_{1}=-3.8$ and $I_{2}=$ -3.6 (Brown, 1988). The bi-directional planetary albedo $\left(R_{i}\right)$ follows from the effective albedo after a correction for the reduction of the solar flux due to the solar zenith angle
$\theta_{0}\left(R_{i}=A_{i} / \cos \theta_{0}\right)$.

The spectrally integrated albedo $R$ was estimated from the band albedos $R_{1}$ and $R_{2}$ as follows:

$$
R=a+b_{1} R_{1}+b_{2} R_{2} .
$$

This relation and values of the coefficients were established by comparing simultaneous and coincident measurements of $R$ and $R_{1}$ and $R_{2}$ performed by the ERBE (Earth Radiation Budget Experiment) and AVHRR radiometers in the region north of $60^{\circ} \mathrm{N}(\mathrm{Li}$ and Leighton, 1992). Since the albedo of each surface has its own spectral distribution, the values of $a, b_{1}$ and $b_{2}$ depend on the surface type. In the present study, the values $a=2.48, b_{1}=0.490$ and $b_{2}=0.699$ were used for a sea surface (explained later in this section), and the values $a=4.53, b_{1}=0.389$ and $b_{2}=0.452$ for snow and ice.

Since all natural surfaces reflect anisotropically and the satellite instrument measures a flow of energy in a particular direction, $R$ is a function of the view angles $\theta$ and $\phi$. The bi-directional albedo should therefore be integrated over the upper hemisphere to obtain the planetary albedo $\alpha_{\mathrm{p}}$ :

$$
\alpha_{\mathrm{p}}=\frac{1}{\pi} \int_{0}^{2 \pi} \int_{0}^{\pi / 2} R\left(\theta^{\prime}, \phi^{\prime}\right) \sin \theta^{\prime} \cos \theta^{\prime} \mathrm{d} \theta^{\prime} \mathrm{d} \phi^{\prime} .
$$

However, $R$ is measured in one direction $(\theta, \phi)$ only. A solution to this problem is to assume that the reflected radiation field is isotropic $(\alpha=R)$ and thereupon apply a correction according to $\alpha^{\prime}=\alpha / f$. The so-called anisotropic correction factor $f$ describes the anisotropy of the reflected radiation field, and depends primarily on the view angles, the solar angles and the physical state of the surface (Rashcke and others, 1973; Taylor and Stowe, 1984). However, distributions of $f(\theta, \phi)$ are neither sufficiently nor accurately known for the partly inhomogeneous ice surface that dominates the ablation zone of the Greenland ice sheet. It is therefore assumed that the reflected radiation field is isotropic $\left(\alpha_{\mathrm{p}}=R\right.$ or $\left.f=1\right)$.

According to the principles of invariance Chandrasekhar, 1960), the relation between planetary albedo $\alpha_{\mathrm{p}}$ and surface albedo $\alpha_{\mathrm{s}}$ is linear:

$$
\alpha_{\mathrm{s}}=c_{1}+c_{2} \alpha_{\mathrm{p}}
$$

Koepke (1989) and Koelemeijer and others (1993), for instance, calculated the values of the coefficients $c_{1}$ and $c_{2}$ by using radiative transfer models which simulate scattering and absorption by the atmospheric constituents. Laborious modelling of the atmosphere can be avoided if the albedo of extensive dark and bright surfaces is known with sufficient accuracy. Using both the surface albedo and the planetary albedo of these surfaces, Equation (4) can be solved for $c_{1}$ and $c_{2}$. The dry snow surface in the interior of the Greenland ice sheet and the sea surface between Canada and Greenland Davis Strait) supplied the data needed for the application of this method. These areas appear to be so homogeneous that tens of thousands of pixels $\left(\mathrm{km}^{2}\right)$ revealed constant planetary albedo. For dry snow, $\alpha_{\mathrm{s}}=0.85$ was assumed. The surface albedo of water was parameterized as a 
function of the solar zenith angle $\theta_{0}$, on the basis of an experimental study of the albedo of the sea surface (Payne, 1972). A third-order polynomial fit to clear-sky data was used:

$$
\begin{aligned}
\alpha_{\mathrm{s}}= & \left(8.07 \times 10^{-2}\right)+\left(1.38 \times 10^{-4} \theta_{0}\right) \\
& -\left(1.99 \times 10^{-5} \theta_{0}{ }^{2}\right)+\left(5.22 \times 10^{-7} \theta_{0}{ }^{3}\right) .
\end{aligned}
$$

Unlike radiative transfer models, this approach does not need any data about the thermodynamic structure of the atmosphere or about the concentrations of various gases and aerosols. Moreover, the method reduces the importance of errors caused by degradation of the AVHRR.

Clear-sky images are the only ones that can be used to study the surface in the visible and near-infrared part of the electromagnetic spectrum. In spite of this severe restriction, 18 images were found to be suitable for compiling a time series (Table 1). Most images were selected on the basis of cloud observations and measurements of global radiation during GIMEX. Nevertheless, cloudy regions were present in some of the images. Objective techniques for detecting clouds from visible and near-infrared satellite radiances often fail in polar regions due to the small visible and thermal contrast between cloud and surface (Ebert, 1987). The cloudy regions were therefore detected visually by examining textural characteristics of the images in combination with ground observations.

The clear-sky images were geometrically corrected by a procedure of so-called inverse referencing or indirect navigation. This method uses orbital models to resample satellite data so that they fit a certain geographical projection. For details, the reader is referred to Klokocník and others (1991). The images were mapped to a grid of $512 \times 512$ pixels, covering the central western part of the Greenland ice sheet from $66^{\circ}$ to $72^{\circ} \mathrm{N}$ and $40^{\circ}$ to $56^{\circ} \mathrm{W}$. This area measures approximately $650 \times 650 \mathrm{~km}^{2}$; the pixel size of the geometrically corrected images is therefore of the same order of magnitude as the AVHRR nadir resolution, and loss of resolution is prevented.

\section{SATELLITE-DERIVED AND IN SITU ALBEDO}

\subsection{Comparison}

In this subsection, the AVHRR-derived albedo $\left(\alpha_{\mathrm{A}}\right)$ will be compared with ground measurements of the albedo at GIMEX sites 5, 6 and $9\left(\alpha_{\mathrm{G}}\right)$. Figure 2 a shows a scatter plot of $\alpha_{\mathrm{A}}$ vs $\alpha_{\mathrm{G}}$. The time-dependent variation in both $\alpha_{\mathrm{G}}$ and $\alpha_{\mathrm{A}}$ is presented in Figure 2b. Near sites 5 and 6, snow patches were present till about 15 June. Site 9 became snow-free around 15 July. Most surface measurements presented in Figure $2 \mathrm{a}$ and $\mathrm{b}$ were therefore performed above ice. More details about the surface conditions will be given in section 4 . The vertical error bars represent the standard deviation $\sigma$ of the $3 \times 3$ neighbourhood of the pixel with the value $\alpha_{\mathrm{A}}$. The error bars were added to indicate uncertainty in the position of the GIMEX sites in the satellite images. In the field, the geographical coordinates of the sites were known accurately (within about $10 \mathrm{~m}$ ) from measurements with the global positioning system (GPS). The geometrically corrected images may have an error that is much larger than the pixel size $(>10 \mathrm{~km})$. The coordinates of all images were therefore fixed to the snout of Russell Glacier

Table 1. An overview of all processed AVHRR scenes and some relevant parameters. The scenes marked with an asterisk are presented in Figure 6. The last six columns refer to Equation (4). The measured planetary albedo $\left(\alpha_{\mathrm{p}}\right)$ and the prescribed surface albedo $\left(\alpha_{\mathrm{s}}\right)$ of dry snow (interior of the Greenland ice sheet) and sea (Davis Strait) are given. The

\begin{tabular}{|c|c|c|c|c|c|c|c|c|}
\hline \multirow[t]{2}{*}{ Date (1991) } & \multirow[t]{2}{*}{ Scene ID } & \multirow{2}{*}{$\begin{array}{c}\text { Time } \\
\text { h UTC }\end{array}$} & \multicolumn{2}{|c|}{ Sea } & \multicolumn{2}{|c|}{ Dry snow } & \multirow[b]{2}{*}{$c_{1}(\%)$} & \multirow[b]{2}{*}{$c_{2}$} \\
\hline & & & $\alpha_{\mathrm{p}}$ & $\alpha_{\mathrm{s}}$ & $\alpha_{\mathrm{p}}$ & $\alpha_{\mathrm{s}}$ & & \\
\hline 10 June & $1033 / 04$ & 15.14 & 0.05 & 0.09 & 0.57 & 0.85 & 1.91 & 1.46 \\
\hline 12 June & $1034 / 02$ & 14.76 & 0.05 & 0.09 & 0.57 & 0.85 & 1.91 & 1.46 \\
\hline 15 June $^{*}$ & $1035 / 07$ & 15.86 & 0.04 & 0.09 & 0.56 & 0.85 & 2.92 & 1.47 \\
\hline 19 June & $1037 / 04$ & 15.09 & 0.05 & 0.09 & 0.55 & 0.85 & 1.17 & 1.52 \\
\hline 24 June* & $1039 / 07$ & 15.81 & 0.05 & 0.08 & 0.54 & 0.85 & 0.63 & 1.56 \\
\hline 1 July $^{*}$ & $1043 / 07$ & 16.15 & 0.05 & 0.09 & 0.56 & 0.85 & 1.11 & 1.50 \\
\hline 6 July & $1045 / 10$ & 15.20 & 0.04 & 0.09 & 0.57 & 0.85 & 3.03 & 1.44 \\
\hline 12 July $^{*}$ & $1048 / 06$ & 15.72 & 0.04 & 0.09 & 0.56 & 0.85 & 3.05 & 1.46 \\
\hline 17 July & $1050 / 09$ & 16.44 & 0.04 & 0.09 & 0.54 & 0.85 & 3.00 & 1.52 \\
\hline 20 July & $1051 / 13$ & 15.87 & 0.05 & 0.09 & 0.55 & 0.85 & 1.12 & 1.53 \\
\hline 25 July* $^{*}$ & $1054 / 03$ & 16.59 & 0.04 & 0.09 & 0.54 & 0.85 & 3.32 & 1.51 \\
\hline 5 August & $1059 / 01$ & 16.15 & 0.04 & 0.10 & 0.55 & 0.85 & 4.36 & 1.47 \\
\hline 8 August" & $1060 / 06$ & 15.58 & 0.05 & 0.10 & 0.56 & 0.85 & 2.27 & 1.48 \\
\hline 30 August & $1070 / 04$ & 16.37 & 0.05 & 0.12 & 0.55 & 0.85 & 4.60 & 1.46 \\
\hline 3 September ${ }^{*}$ & $1071 / 11$ & 15.61 & 0.06 & 0.12 & 0.55 & 0.85 & 3.35 & 1.48 \\
\hline 17 September & $1076 / 11$ & 16.26 & 0.06 & 0.14 & 0.52 & 0.85 & 4.53 & 1.55 \\
\hline 20 September & $1077 / 11$ & 15.68 & 0.06 & 0.14 & 0.53 & 0.85 & 4.79 & 1.51 \\
\hline 27 September" & $1080 / 06$ & 16.01 & 0.06 & 0.16 & 0.52 & 0.85 & 6.76 & 1.50 \\
\hline
\end{tabular}
variation in the albedo of the sea surface reflects the dependency on the solar zenith angle (Equation (5)) 

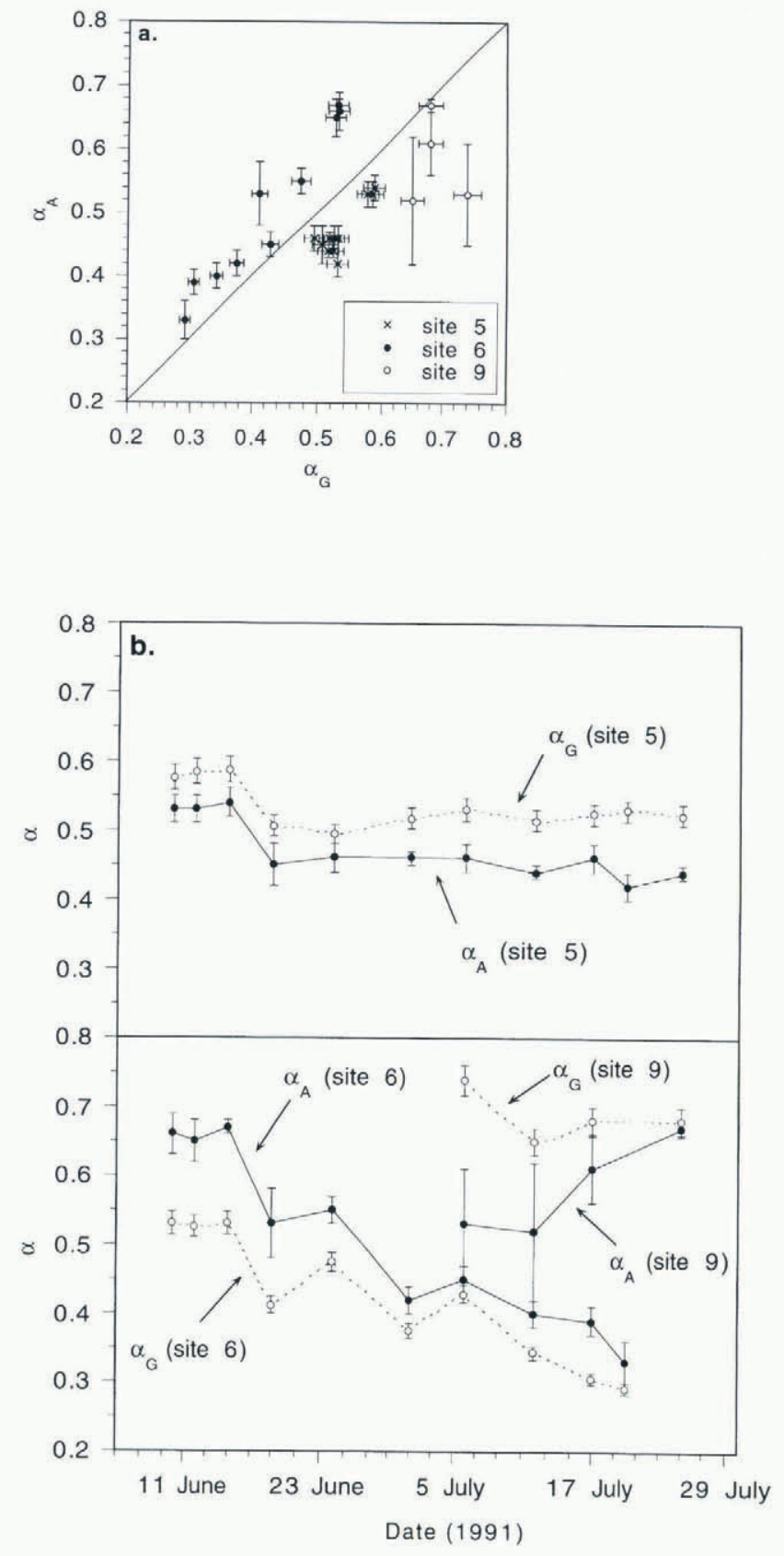

Fig. 2. (a) AVHRR-derived albedo $\left(\alpha_{\mathrm{A}}\right)$ us ground albedo $\left(\alpha_{\mathrm{G}}\right)$ at GIMEX sites 5, 6 and 9 (Fig. 1). The error bars in $\alpha_{\mathrm{G}}$ represent the measuring error. The AVHRR-derived albedo is presented as the central ground element of a set of nine elements. The error bar in each value is the standard deviation of the distribution of the nine values. (b) Time-dependent variation in $\alpha_{\mathrm{A}}$ and $\alpha_{\mathrm{G}}$.

(Fig. 1). It is estimated that the GPS coordinates of the sites are situated in areas of $3 \times 3$ pixels. Hence, $\alpha_{\mathrm{G}}$ is presented with error bars which represent the standard deviation of 9 pixels.

At site $5, \alpha_{\mathrm{A}}$ is systematically lower than $\alpha_{\mathrm{G}}$ (Fig. 2a). The average difference is 0.07 . The temporal variation in $\alpha_{\mathrm{G}}$ is close to that in $\alpha_{\mathrm{A}}$, although the satellite-derived albedo drifts slowly away from the in situ albedo towards the end of the measuring period (Fig. 2b). At site 6, the situation is reversed: $\alpha_{\mathrm{A}}$ is always higher than $\alpha_{\mathrm{G}}$, the average difference being 0.08. Again, the temporal variation in the satellite-derived albedo is consistent with the ground observations, although there is some convergence as time passes. As will be suggested in section 4 , the tremendous decrease in the albedo is related to the accumulation of meltwater at the ice surface. At site 9 (as at site 5) $\alpha_{\mathrm{A}}$ underestimates $\alpha_{\mathrm{G}}$. The large error bars indicate that the surface around site 9 is very inhomogeneous, which interferes with a comparison of $\alpha_{\mathrm{A}}$ and $\alpha_{\mathrm{G}}$. However, during the second half of July, the inhomogeneity diminishes $(\sigma<0.01)$ and the values converge to approximately 0.68 (Fig. 2b). This is an extremely high albedo for an ice surface.

\subsection{Analysis of differences}

The differences between $\alpha_{\mathrm{A}}$ and $\alpha_{\mathrm{G}}$ are too large to be attributed to a measuring error in the ground observations of the short-wave fluxes, which is of the order of $2 \%$. Furthermore, the values of $\sigma$ are generally not large enough to explain the differences in terms of spatial variation in the albedo on the scale of several pixels, i.e. several square kilometres (see error bars in Figure 2a and b). The discrepancy between $\alpha_{\mathrm{A}}$ and $\alpha_{\mathrm{G}}$ may therefore be explained in terms of errors introduced by the retrieval method (section 2). Errors associated with Equations (2), (3) and (4) will be examined in turn.

Since Li and Leighton (1992) do not distinguish between ice and snow, it is obvious that a certain error has been introduced by the application of Equation (2). To establish the sensitivity of the albedo to changes in the coefficients of Equation (2), the set of constants corresponding to ice and snow was replaced by the constants that were used for the sea surface. Figure 3 shows a scatter plot of the adjusted albedo against the initial values along the GIMEX transect on 25 July. These data were selected in order to cover a wide range of albedo values, corresponding to a variety of surface conditions. This exercise shows a relatively small decrease in the albedo, by an average of 0.01 . The largest decrease is 0.03 . This is too small to explain the differences between $\alpha_{\mathrm{A}}$ and $\alpha_{\mathrm{G}}$. In general, the albedo will be rather insensitive to changes in the coefficients in Equation (2). This is an immediate result

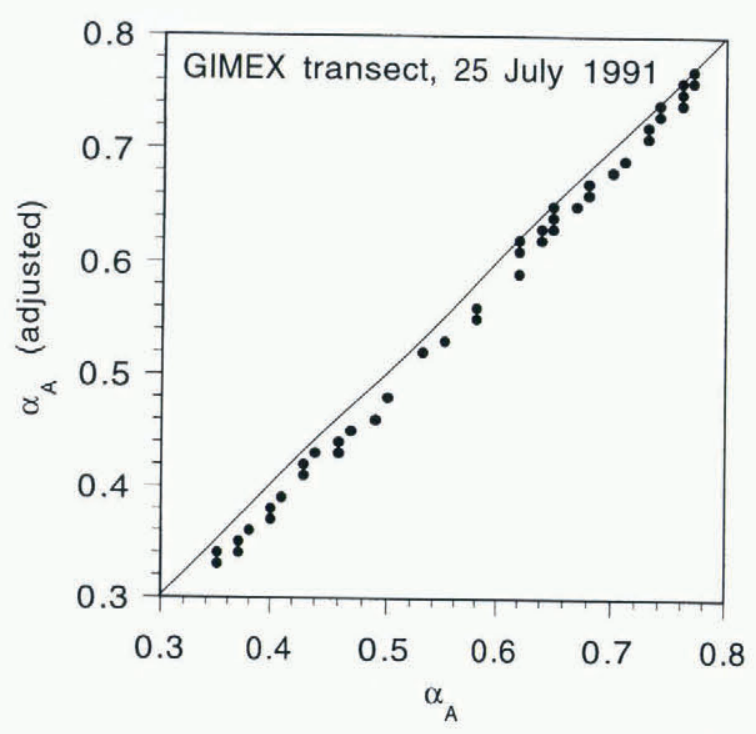

Fig. 3. Adjusted AVHRR-derived albedo $\left(\alpha_{\mathrm{A}}\right)$, calculated by using the constants for the sea surface (see Equation (2) and text) os the original data. 


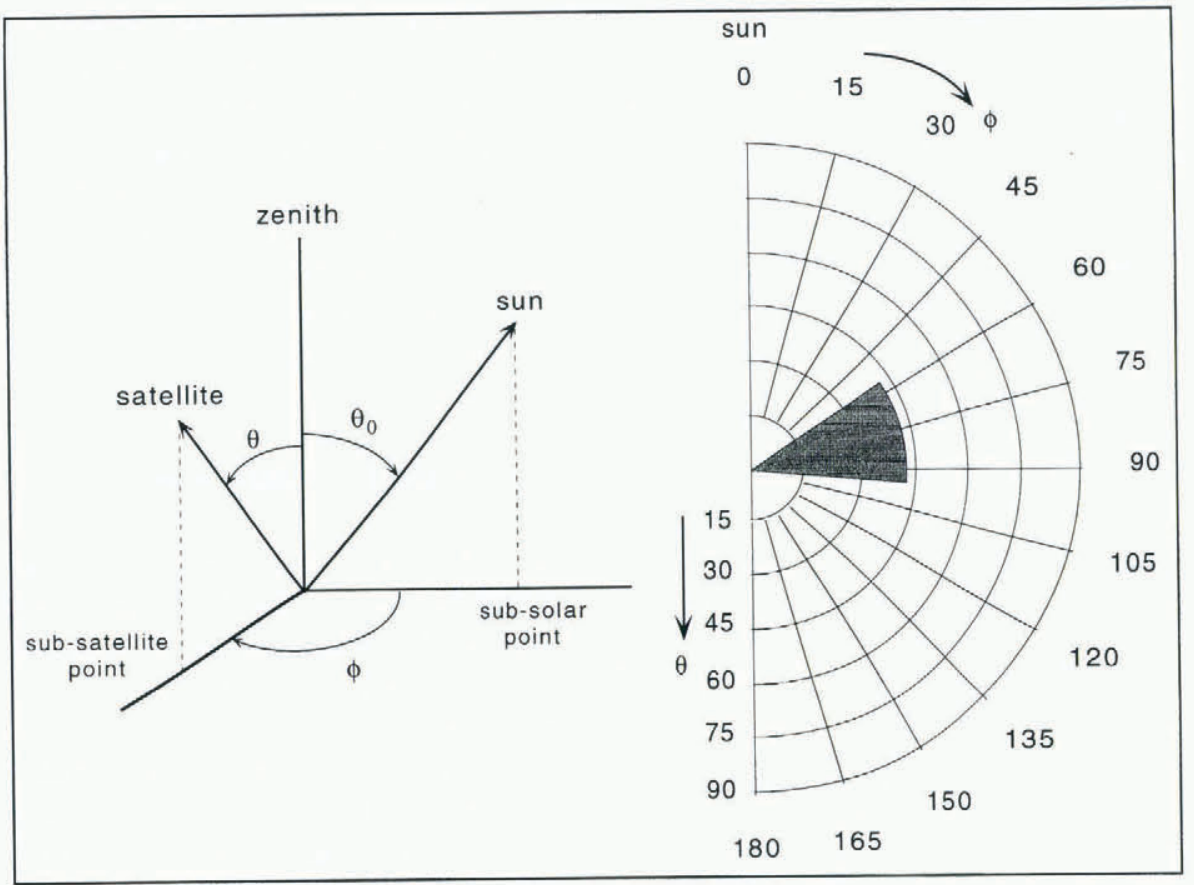

Fig. 4. Satellite and solar geometry (left) and polar diagram (right). The radial coordinate represents the satellite zenith angle $(\theta)$. The azimuth angle $(\phi)$ is calculated relative to the solar principal plane, i.e. the sun is always siluated at $0^{\circ}$. The dark sector indicates the view geometry of the AVHRR at the time of the nine selected passes (Table 1).

of prescribing the surface albedos of sea and dry snow in Equation (4). The effect of a change in the coefficients $a, b_{1}$ and $b_{2}$ (Equation (2)) is compensated by an adjustment of the coefficients $c_{1}$ and $c_{2}$ (Equation (4)). For the same reason, the albedo is insensitive to changes in the calibration coefficients (Equation (1)).

The assumption that the reflected radiation field is isotropic was examined in view of patterns of bidirectional reflectance of snow and water, constructed by Taylor and Stowe (1984). These patterns were selected because the unknown pattern of the surface within the study area may resemble the pattern of snow (a rather isotropic reflector) or of water (a highly anisotropic reflector), depending on the actual conditions of the surface. Snow surfaces (observed mainly from the Antarctic and Greenland ice sheets) were found to reflect almost isotropically at solar zenith angles of less than about $66^{\circ}$. The solar zenith angles at the time of the NOAA passes are substantially smaller and vary between $46^{\circ}$ and $49^{\circ}$. Apart from the solar angles, the view geometry of the satellite instrument determines the error introduced by the isotropic assumption. Figure 4 shows a polar diagram of this geometry. Most measurements are performed more or less sideways $\left(\phi \approx 90^{\circ}\right)$, i.e. perpendicular to the solar principal plane. The zenith angles are not very large $\left(\theta<42^{\circ}\right)$. Due to forward scattering of radiation at the surface and below it, anisotropy is especially pronounced in the specular direction $\left(\phi \approx 180^{\circ}\right)$ at large zenith angles $\left(\theta \approx 90^{\circ}\right)$. This indicates that the view angles shown in Figure 4 are situated within a rather favourable area of the polar diagram. Nevertheless, the reflectance pattern of water suggests that the isotropic assumption leads to a certain degree of underestimation of the real albedo $(f<1$; see section 2). Correcting for this would increase the albedo. Since the reflected radiation field above the surface around site 6 may resemble the pattern of water (section 4), $\alpha_{\mathrm{A}}$ at site 6 is expected to improve as a result of a correction. Unfortunately, the opposite is true and the difference between $\alpha_{\mathrm{A}}$ and $\alpha_{\mathrm{G}}$ increases. If the reflected radiation field were strongly anisotropic, one might expect to find strong correlation between $\alpha_{\mathrm{A}}-\alpha_{\mathrm{G}}$ and the satellite view angles. According to Figure 5, there is no evidence for a significant correlation. All this gives us the impression that the assumption of isotropic surface reflection is not the main factor causing the differences between $\alpha_{\mathrm{A}}$ and $\alpha_{\mathrm{G}}$.

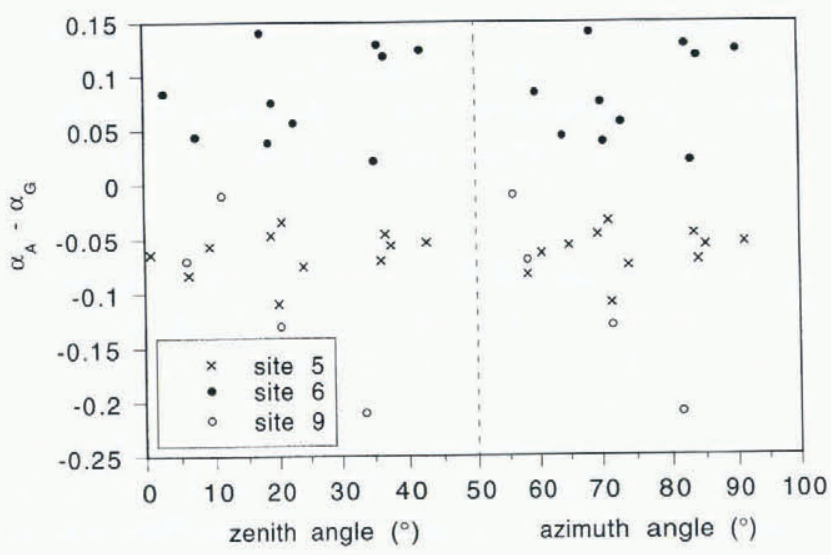

Fig. 5. The difference between AVHRR-derived albedo $\left(\alpha_{\mathrm{A}}\right)$ and GIMEX albedo $\left(\alpha_{\mathrm{G}}\right)$ (Fig. 7) vs the satellite zenith angle (left) and the satellite azimuth angle (right). The azimuth angle is calculated relative to the solar principal plane (see Fig. 4). 
The values of the coefficients $c_{1}$ and $c_{2}$ (Equation (4); Table 1) depend on the choice of the prescribed surface albedos of dry snow and sea. A realistic adjustment of \pm 0.05 is not enough to reduce the difference between $\alpha_{\mathrm{A}}$ and $\alpha_{\mathrm{G}}$. Moreover, this change decreases or increases $\alpha_{\mathrm{A}}$ at all sites, which is obviously undesirable. Sensitivity experiments with a two-stream multiple-scattering radiative model of a cloud-free atmosphere Koelemeijer, 1992) showed that the influence of the atmosphere is rather small and that the differences between $\alpha_{\mathrm{A}}$ and $\alpha_{\mathrm{G}}$ cannot be attributed to the atmospheric correction. Note that the large difference between planetary and surface albedo (Table 1) is due not only to atmospheric interference but also to degradation of the AVHRR.

It seems that crucial assumptions made in the retrieval method do not conclusively explain the difference between the satellite-derived and the ground albedo. We therefore suggest that the deviations are caused mainly by real differences introduced by sub-pixel variation in the albedo. The downward-facing sensor of the ground instruments receives most of the reflected radiation from an area that is of the order of $10 \mathrm{~m} \times 10 \mathrm{~m}$. By contrast, the ground resolution of the AVHRR is
$1.1 \mathrm{~km}$ at nadir, and this resolution becomes coarser with increasing viewing angle off-nadir. The largest pixel size within the raw images is approximately $1.7 \mathrm{~km} \times 2.5 \mathrm{~km}$. The AVHRR resolution is therefore much too coarse to observe variation in the albedo on a scale of several hundreds or thousands of square metres, which is a realistic variation in the ablation area of the Greenland ice sheet.

\section{DESCRIPTION OF SATELLITE-DERIVED ALBEDO}

\subsection{Temporal and spatial variation}

In this subsection a brief description is given of the temporal and spatial variation in the surface albedo in the Sondre Stromfjord area. The main features are presented in Figure 6 (images of the entire study area) and Figure 7 (data of the GIMEX transect only). The positions of GIMEX sites 5, 6 and 9 are indicated. The time series is a representative selection of nine scenes (Table 1) which shows significant changes during the ablation period of 1991. The albedo data along the GIMEX transect (Fig.
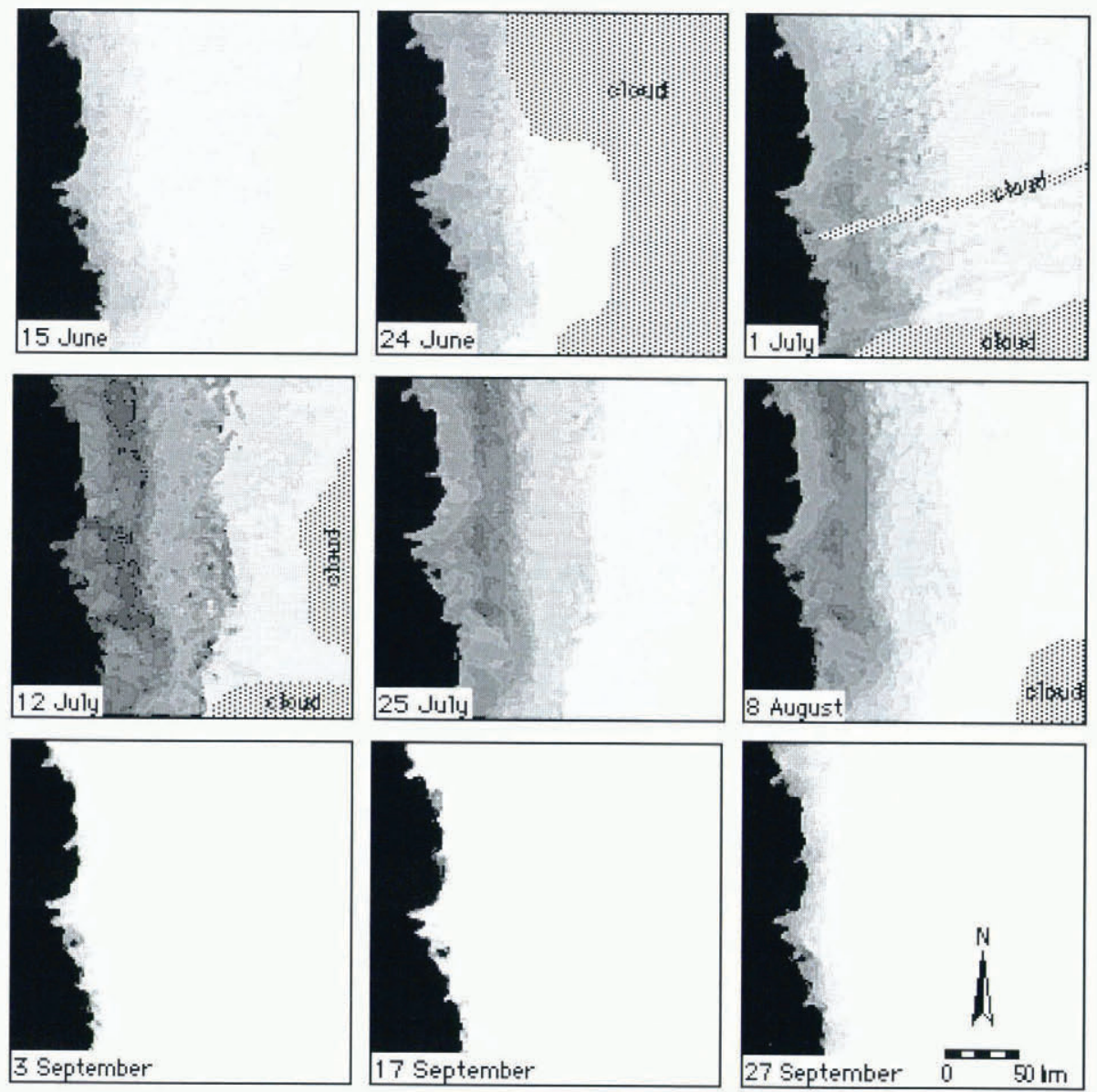

Surface albedo

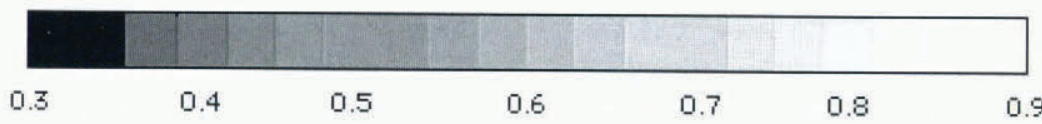

Fig. 6. AVHRR-derived horizontal distribution of the surface albedo during the ablation season of 1991. The quality of the images was enhanced by a $3 \times 3$ median and an edge-enhancement filter, successively (see, e.g., Cracknell and Hayes, 1991). Cloudy areas above the ice sheet are indicated. The albedo of the tundra is set to values $<0.3$. A geographical map of the area is given in Figure 1. 


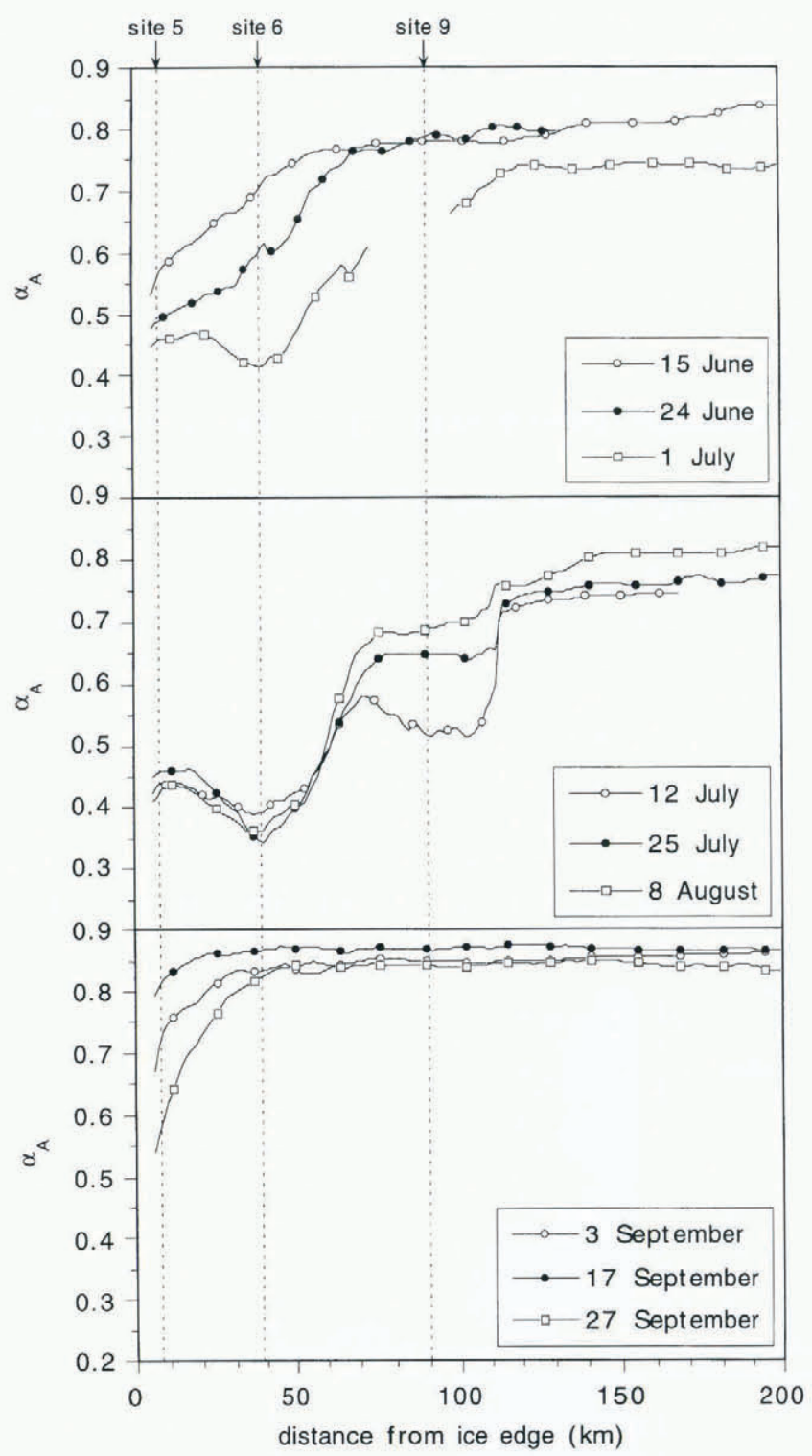

Fig. 7. AVHRR-derived surface albedo $\left(\alpha_{\mathrm{A}}\right)$ along the GIMEX transect $\left(67^{\circ} \mathcal{N}\right)$ during the ablation season of 1991. Gaps in the data of 1 and 12 July are due to cloudiness.

7) were extracted from the raw albedo files as the means of five rows centred on the latitude of Russell Glacier (approximately $67^{\circ} \mathrm{N}$; see Fig. 1). A five-point running mean was applied in order to obtain a good representation of the general albedo profile.

On 15 June the albedo of the study area is generally high, except in a zone near and parallel to the ice edge. Along the transect (Fig. 7) the albedo gradually increases from 0.53 near the ice edge to almost 0.85 at $200 \mathrm{~km}$. The surface near the upper limit of the profile $(2100 \mathrm{~m}$ a.s.l.) very probably consists of dry snow at the beginning of the melt season. Near the ice edge the previous winter's snowpack has melted away and bare ice has emerged at the surface. This is confirmed by GIMEX observations at site 5 (Fig. 1). In view of the gradually increasing albedo in the first $50 \mathrm{~km}$ along the transect there is not yet a distinct boundary between ice and snow. The transition from bare ice near the ice edge to snow higher up on the ice sheet is marked by a broad zone of patches of wet snow, slush and ice. With increasing altitude the surface becomes more dominated by snow, which causes the gradual albedo increase. On 24 June, i.e. a week or more after the first image, an average albedo decrease of 0.1 is observed over the first $70 \mathrm{~km}$ of the transect. The lower parts of the transect are now completely free of snow. A further decrease of the albedo can be observed on 1 July. Striking is the appearance of a dark area extending in north-south direction, east of the large outlet glaciers (Isunguata sermia, Russell Glacier, etc.). Further development of this dark area in north-south direction and a tremendous decrease in the albedo over the entire study area can be observed on 12 July. The dark band shows up distinctively as a broad dip in the albedo profile centred at about $40 \mathrm{~km}$ from the ice edge (Fig. 7). Oerlemans and Vugts (1993) state that this dark band should be associated with the accumulation of meltwater at the glacier surface (see section 4.2). East of the dark band another zone can be distinguished in which we find isolated pixels of very low albedo (Fig. 6). These are probably caused by supraglacial meltwater lakes that have formed in topographical depressions. Typical lake sizes of several square kilometres match well with the size of individual pixels. The frequent occurrence of low albedos within the image of 12 July comes abruptly to an end about $110 \mathrm{~km}$ from the ice edge (Fig. 7). Over a short distance the albedo increases from 0.52 to 0.70 . Most probably, the transient snow-line is found here.

Although the albedo is generally higher on 25 July, the albedo distribution on this day shows the same remarkably regular pattern as on 12 July. Apparently the albedo develops into a pattern of zones which lie more or less parallel to the ice edge. The last cloud-free day on which the typical zonation can be distinguished is 8 August (Fig. 6). The last three images (3, 17 and 27 September) show that the regular pattern has been replaced by a fairly uniform area with high albedo values. Undoubtedly this is due to fresh snow covering the glacier surface. However, the albedo tends to decrease near the ice edge on 27 September. This might be caused by melting of new snow or by strong winds that expose bare ice and lower the albedo.

\subsection{Distribution of zones in the Søndre Strømfjord area}

A conspicuous feature of the albedo pattern discussed in section 4.1 is the dark band. A direct consequence of the existence of this band is that the albedo decreases (locally) with increasing altitude. This is quite remarkable in view of the fact that on alpine glaciers the albedo usually increases from the snout to the head of the glacier. In this subsection we go further into the typical zonation in the Søndre Strømfjord area. A probable description of the surface within the zones is given in the light of the image of 25 July (Fig. 6). This image was selected because of the obvious presence of the zones and because subsequent images fall outside the measuring period of GIMEX. Figure 8 gives a characterisation of the albedo pattern along the GIMEX profile in terms of four zones indicated by Roman numerals I-IV. GIMEX sites 5, 6 and 9 are situated within zones I, II and III, respectively. Some details about the individual zones are summarised in Table 2. 


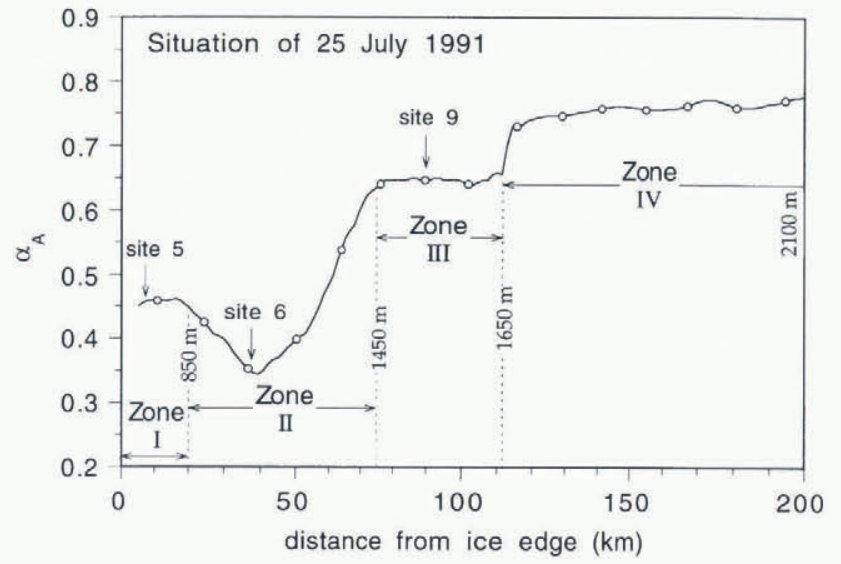

Fig. 8. AVHRR-derived surface albedo $\left(\alpha_{\mathrm{A}}\right)$ along the GIMEX transect $\left(67^{\circ} \mathrm{N}\right)$ on 25 . July 1991. The vertical dotted lines represent the boundaries between the different zones (see text). Altitudes ( $m$ a.s.l.) of the boundaries are added (vertically).

Zone I represents the first $20 \mathrm{~km}$ of the GIMEX transect. Most meltwater which arises at the hilly surface of this zone is drained efficiently by a complex system of crevasses and moulins. The concentration of debris and till at the bare-ice surface is rather small compared to the amount of morainic material usually found at the surface of an alpine glacier. Because of the small concentration of water and supraglacial material, the ice is relatively dry and clean. This contributes to the fact that zone I looks quite bright on the image (Fig. 6).

Zone II, which includes the dark band, extends between 20 and $75 \mathrm{~km}$ from the ice edge. The albedo reaches values as low as 0.34 , substantially lower than the albedo of zone I. As the deeper ice in zone II is cold, i.e. not at melting temperature, an effective internal drainage system does not develop and most meltwater drains supraglacially. If the surface slope is sufficiently small, meltwater accumulates on the ice surface. This process may explain the steady decrease of the albedo at site 6 (Fig. 2b) in the course of the melt season. Figure 9 gives some indirect evidence for a relation between low albedos and surface meltwater. It appears that the albedo minimum at $40 \mathrm{~km}$ from the ice edge coincides with a local minimum in the surface slope. That drainage and surface slope are closely related was recognised by Zuo and Oerlemans (1996) who attempted to model the albedo along the GIMEX transect. On 12 July, zone II

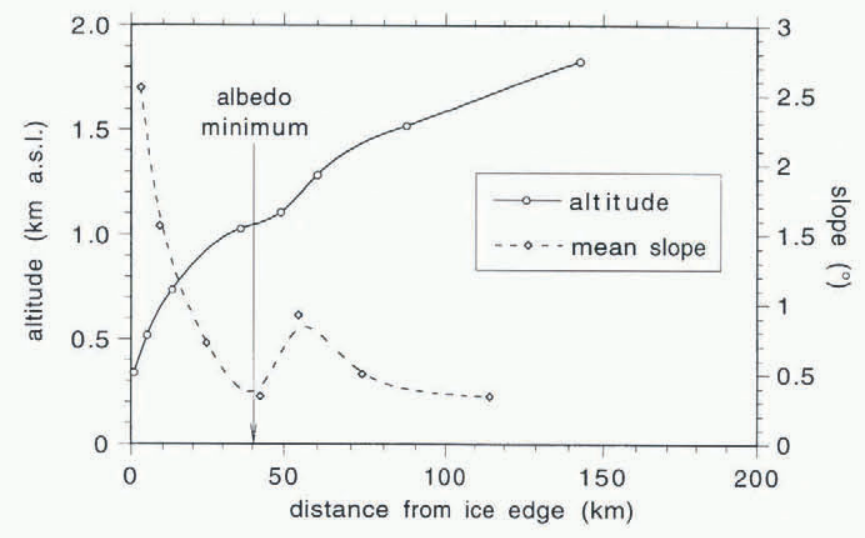

Fig. 9. Altitude and mean slope profile of the GIMEX transect, as inferred from differential GPS (global positioning system) measurements in 1991. The arrow indicates the situation of the albedo minimum derived from satellite measurements (Fig. 8).

seems to be even more pronounced than on 25 July (Fig. $6)$. In general, the albedo is lower and the dark band spreads over zone I. This feature might occur during a period of intense ablation.

Zone III was chosen on the basis of its rather constant albedo (about 0.65) on 25 July (Fig. 8; Table 2). The upper boundary of the zone $(110 \mathrm{~km}$ from the ice edge or $1650 \mathrm{~m}$ a.s.l.) is most probably the transient snow-line. Zone III therefore consists entirely of ice with an extremely high albedo. Site 9 of GIMEX (Fig. 1) was situated in the middle of zone III. Snow-depth measurements at this station showed that the previous winter's snow cover disappeared on 15 July (Henneken and others, 1994). Subsequently, the ice layer dried and fragmented into little bars $(48 \mathrm{~cm}$ long) with an angular structure. This typical structure indicates that at the time of observation the surface of site 9 consisted of superimposed ice. It seems that the same type of ice was found at the Swiss ETH camp in July 1990 Konzelmann, 1994). Konzelmann refers to it as "candle ice" and also suggests that it is superimposed ice.

The consistency of the albedo in zone III and the observations at site 9 bring us to the hypothesis that zone III is the superimposed-ice zone. Benson (1961) classified this zone on the basis of field observations made near the western margin of the Greenland ice sheet from 1952 to 1955. The hypothesis will be further investigated in view

Table 2. Summary of zones found along the GIMEX transect on 25 July 1991. See also Figure 8. The third column refers to distances from the ice edge. The surface types as presented in the last column are discussed in the text (section 4.2)

\begin{tabular}{|c|c|c|c|c|c|c|}
\hline \multirow[t]{2}{*}{ Zone } & Altitude & Dislance & & Albedo & & Surface type \\
\hline & m a.s.l. & $\mathrm{km}$ & Lowest & Highest & Mean & \\
\hline I & $300-850$ & $0-20$ & 0.45 & 0.46 & 0.46 & Clean dry ice \\
\hline II & $850-1450$ & $20-75$ & 0.34 & 0.63 & 0.45 & Ice with surface water \\
\hline III & $1450-1650$ & $75-110$ & 0.63 & 0.66 & 0.65 & Superimposed ice \\
\hline IV & $1650-2100$ & $110-200$ & 0.66 & 0.78 & 0.75 & Snow \\
\hline
\end{tabular}


of the upper and lower boundaries of zone III. According to the concept of glacier zones Benson, 1961; Paterson, 1994) the upper boundary of the superimposed-ice zone is the snow-line. As the ablation season progresses, the transitional area between ice and snow becomes narrower. This results in a rather sudden increase in the albedo. We can therefore state with certainty that the stepwise increase of the albedo at $1650 \mathrm{~m}$ a.s.l. (Fig. 8) is associated with the snow-line. Within the superimposedice zone there is an annual increment of superimposed ice. The zone is therefore part of the accumulation area. Below the lower boundary of the superimposed-ice zone there is net loss of mass over a year. The lower boundary of the superimposed-ice zone is therefore the equilibrium line. Bearing this in mind, it is useful to compare the lower boundary of zone III with the ELA, inferred from stake measurements (Table 3). The ELA for the 1990-91

Table 3. Equilibrium-line altitudes (ELAs) of the GIMEX transect, inferred from stake measurements over the period 1990-94 (van de Wal and others, in press). The average ELA is $1420 \mathrm{~m}$ a.s.l.

\begin{tabular}{cc}
\hline Year & ELA \\
& ma.s.1. \\
\hline $1990-91$ & 1575 \\
$1991-92$ & 1205 \\
$1992-93$ & 1440 \\
$1993-94$ & 1465 \\
\hline
\end{tabular}

balance year ( $1575 \mathrm{~m}$ a.s.l.) is rather high compared to the lower boundary of zone III ( $1450 \mathrm{~m}$ a.s.l.). This could imply that superimposed ice is found below the equilibrium line, which is not impossible since the ablation season is generally not finished by 25 July. However, the lower boundary of zone III, as derived from subsequent images, did not approach the 1990-91 ELA. Large interannual variation in the ELA may be the reason that superimposed ice is found well below the equilibrium line. A substantial increase of the ELA could expose superimposed ice formed during previous years. The fact that the 1990-91 ELA is relatively high (Table 3) gives some support for this idea. The formation of superimposed ice during successive summers (instead of during one summer) could therefore determine the lower boundary of the superimposed-ice zone in the Sondre Stromfjord area. For this reason, the lower boundary of zone III should be compared with the mean ELA, averaged over several years. The available data (Table 3) give a mean ELA of 1420 ma.s.l. which corresponds fairly well to the lower boundary of zone III (1450 m a.s.1.).

Zone IV consists of snow. It is common to distinguish the dry-snow zone, the percolation zone and the wet-snow zone (Benson, 1961; Paterson, 1994). According to Benson (1961), the dry-snow zone in Greenland roughly coincides with the region where the mean annual air temperature is $-25^{\circ} \mathrm{C}$ or lower. At the upper boundary of the profile $(2100 \mathrm{~m}$ a.s.l. $)$ the mean annual air temperature is substantially higher than $-25^{\circ} \mathrm{C}$ (Ohmura, 1987). Zone IV therefore does not extend to the dry-snow zone. The percolation zone and the wet-snow zone are distinguished on the basis of sub-surface characteristics. It is highly unlikely that these are visible in the albedo distribution.

\subsection{Distribution of zones between $63^{\circ}$ and $71^{\circ} \mathrm{N}$}

The typical albedo distribution within the study area leads obviously to questions about the extent of this pattern. Therefore, we briefly discuss the albedo of the southwestern part of the Greenland ice sheet as it was on 25 July 1991 (Fig. 10). The western margin of the ice sheet is cloud-free and the ice edge is clearly visible between $63^{\circ}$ and $71^{\circ} \mathrm{N}$ latitude. The typical zonation as described in section 4.2 extends roughly between $66^{\circ}$ and $70^{\circ} \mathrm{N}$. In the southern part, zone II (the dark band) bends towards the ice edge, whereas zone III (probably superimposed ice) becomes broader. Just north of $65^{\circ} \mathrm{N}$,
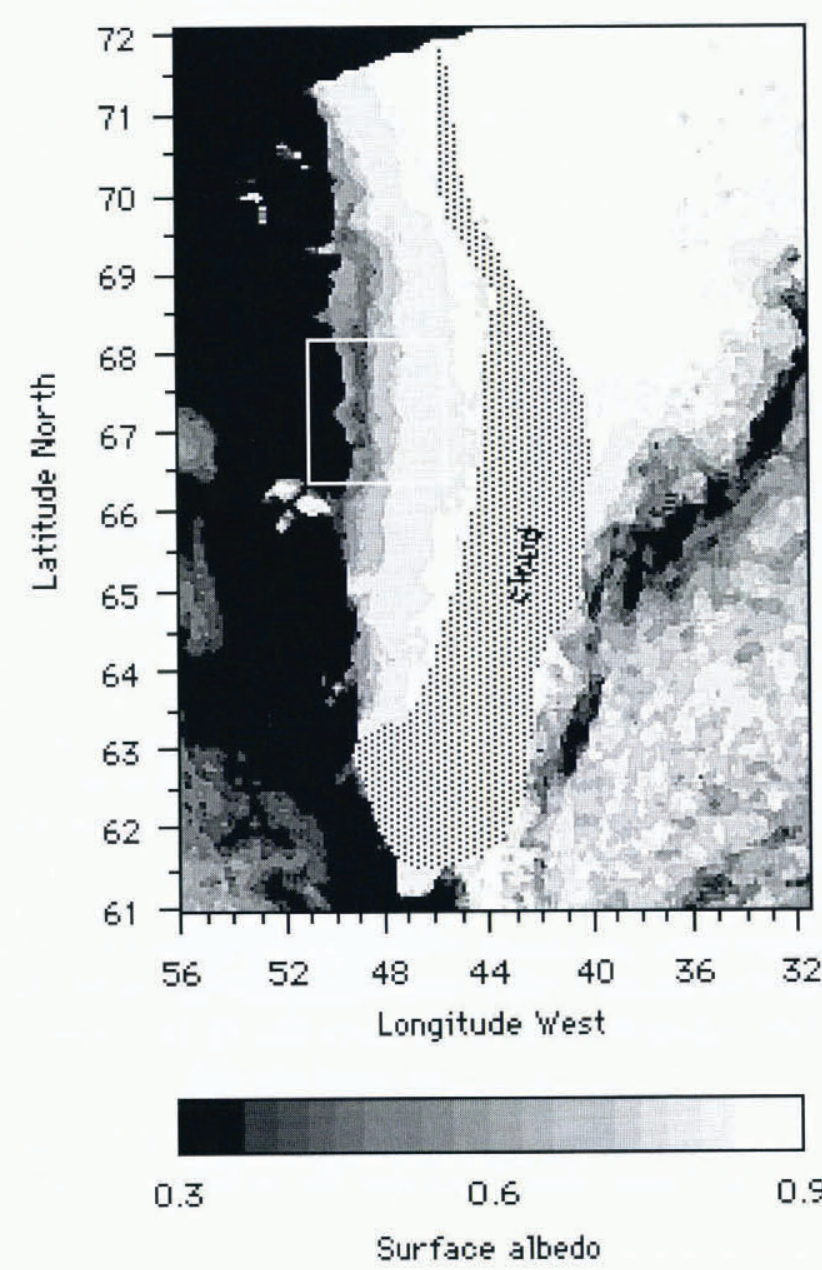

Fig. 10. AVHRR-derived surface albedo of the Greenland ice sheet south of $72^{\circ} \mathrm{N}$ on $25 \mathrm{July} 1991$. A significant part of the inland ice is obscured by clouds (smooth grey area). Clouds are also visible above the Atlantic Ocean (southeastern part of the image). The white square shows the study area (Fig. 1). The glacierized Sukkertoppen show up as bright clusters just outside the southwestern corner of the study area. 
zone II becomes very narrow and eventually disappears. This may be related to the steep surface south of the Sukkertoppen mountain range which prevents accumulation of meltwater at the surface. In the area of Jakobshavns Isbræ $\left(69^{\circ}-69^{\circ} 30^{\prime} \mathrm{N}\right)$, the zonation is squeezed westwards and zone II extends to the ice edge. Meltwater therefore seems to be poorly drained at the surface of the lower catchment area of Jakobshavns Isbræ. Zone II is visible up to a latitude of about $70^{\circ} \mathrm{N}$ and disappears rather suddenly. Zone III narrows in the area of Jakobshavns Isbræ, which may imply that the superimposed-ice zone is not as broad as in the Søndre Stromfjord area.

Explaining all regional variations of the albedo shown in Figure 10 is a task which goes beyond the scope of this paper. The figure nevertheless demonstrates convincingly that the zonation exists on a fairly large scale and is not limited to the immediate surroundings of Sondre Stromfjord.

\section{DISCUSSION AND CONCLUDING REMARKS}

Despite the simplicity of the retrieval method presented here, our results show that realistic values of the surface albedo can be derived from visible and near-infrared radiances measured by the AVHRR. The fact that the temporal variation in the satellite-derived albedo at sites 5 and 6 is consistent with the in situ albedo (Fig. 2b) inspires confidence in the method. Nevertheless, the measurements at all three sites show that large systematic differences are common. Because the AVHRR resolution $(\geq 1.1 \mathrm{~km})$ is so coarse compared to the field of view of the ground instruments, it is difficult to draw a firm conclusion regarding the accuracy of the satellite-derived albedo. Satellite and ground measurements performed simultaneously at equal scales may provide more insight into this. Instruments with finer ground resolution (e.g. Landsat TM $(30 \mathrm{~m})$ or RESURS-01 MSU-SK multispectral scanner $(170 \mathrm{~m})$ ) may be used to determine whether sub-pixel variation in the albedo in the Sondre Stromfjord area is indeed large enough to explain the differences between satellite-derived and in situ albedos.

On the basis of remotely sensed data of Brúarjökull (a surge-type outlet glacier of Vatnajökull, Iceland), Williams and others (1991) combined glacier ice and superimposed ice into one ice zone. In contrast with this work, we distinguished three zones below the snow-line in the Sondre Stromfjord area (Fig. 8; Table 2). The occurrence of zones II and III (probably ice with surface water and superimposed ice, respectively) may be attributed to non-temperate conditions. The temperature of the ice is below $0^{\circ} \mathrm{C}$ (except for a surface layer), which prevents the development of an effective internal drainage system. Consequently, meltwater can accumulate on the ice surface. Superimposed ice forms only if firn temperatures are below $0^{\circ} \mathrm{C}$. Since Vatnajökull is a temperate ice cap, zones II and III may simply not exist.

The satellite-derived albedo at site 6 roughly halves in the course of the melt season (Fig. 2b). Energy-balance calculations for this site showed that $80-90 \%$ of the energy available for melting comes from solar radiation (van de Wal, 1992). The development of zone II therefore has serious consequences for the mass balance in the region of Søndre Stromfjord. Yearly variation in temperature and precipitation, for example, is likely to affect the development of the zones and the altitude of the boundaries. Longterm monitoring of the albedo pattern by satellites may therefore be a useful technique for studying the interaction between the climate system and the ice sheet. Nevertheless, surface measurements should continue in order to verify for instance the suggested relation between the lower boundary of zone III and the ELA.

\section{AGKNOWLEDGEMENTS}

We thank P. Schlüssel (Max Planck Institut für Meteorologie, Hamburg, Germany) for putting the geolocation software at our disposal. S. Tjemkes (EUMETSAT, Germany) did preparative work. N. Lonie (Satellite Station, University of Dundee, U.K.) provided us with the AVHRR imagery. T. Kelso (Air Force Institute of Technology, Alabama, U.S.A.) selected the orbital elements. N. -J. Bink (Free University of Amsterdam, The Netherlands) supplied us with information about surface conditions at GIMEX site 9. W. Greuell and R. van de Wal (Institute for Marine and Atmospheric Research Utrecht, Utrecht University, The Netherlands) are thanked for useful comments. Financial support for this project was provided by the Space Research Organisation Netherlands (SRON).

\section{REFERENCES}

Abel, P. 1990. Prelaunch calibration of NOAA-11 AVHRR visible and near IR channels. Remote Sensing Environ., 31, 227-229.

Ambach, W. 1963. Untersuchungen zum Energieumsatz in der Ablationszone des grönländischen Inlandeises Camp IV-EGIG, $69^{\circ} 40^{\prime} 05^{\prime \prime}$ N, $49^{\circ} 37^{\prime} 58^{\prime \prime}$ W). Medd. Gronl., $174(4)$.

Benson, C. S. 1961. Stratigraphic studies in the snow and firn of the Greenland ice sheet. Folia Geogr. Dan., 9, 13-37.

Brown, S. R. 1988. Amendment to NOAA Technical Memorandum 107. Washington, DC, National Oceanic and Atmospheric Administration. Appendix B for NOAA-H/11.

Chandrasekhar, S. 1960. Radiative transfer. New York, Dover Publications.

Cracknell, A. P. and L. W. B. Hayes. 1991. Introduction to remote sensing. London, Taylor and Francis.

Ebert, E. 1987. A pattern recognition technique for distinguishing surface and cloud types in the polar regions. J. Climate Appl. Meteorol., $26(10), 1412-1427$.

Greuell, W. 1992. Numerical modelling of the energy balance and the englacial temperature at the ETH camp, West Greenland. Zürcher Geogr. Schr. 51.

Henneken, E. A. C., N.J. Bink, H.F. Vugts, F. Cannemeijer and A. G. C. A. Meesters. 1994. A case study of the daily energy balance near the equilibrium line on the Greenland ice sheet. Global and Planetary Change, 9 1-2), 69-78.

Klokocník, J., P. Schlüssel, J. Kostelecky and H. Grassl. 1991. On the navigation of polar orbiting meteorological satellites. Hamburg, MaxPlanck-Institut für Meteorologie. (Report 75.

Koelemeijer, R. 1992. Determination of the surface albedo of Hintereisferner with Landsat thematic mapper data. Utrecht, Utrecht University. (IMAU Report.

Koelemeijer, R., J. Oerlemans and S. Tjemkes. 1993. Surface reflectance of Hintereisferner, Austria, from Landsat 5 TM imagery. Ann. Glaciol., 17, 17-22.

Koepke, P. 1989. Removal of atmospheric effects from AVHRR albedos. j. Appl. Meteorol., 28, 1341-1348.

Konzelmann, T. 1994. Radiation conditions on the Greenland ice sheet. Zürcher Geogr. Schr. 56. 
Lauritson, L., G.J. Nelson and F.W. Porto. 1979. Data extraction and calibration of TIROS-N/NOAA radiometers. Washington, DC, National Oceanic and Atmospheric Administration. (NOAA Tech. memo. NESS-107.

Li, Z. and H. G. Leighton. 1992. Narrowband to broadband conversion with autocorrelated reflectance measurements. F. Appl. Meleorol., 31 (5), 421-432.

Oerlemans, J. and H.F. Vugts. 1993. A meteorological experiment in the melting zone of the Greenland ice sheet. Bull. Am. Meteorol. Soc., $\mathbf{7 4}(3), 355-365$.

Ohmura, A. 1987. New temperature distribution maps for Greenland. Z Gletscherkd. Glazialgeol., 23 (1), 1-45.

Paterson, W. S. B. 1994. The physics of glaciers. Third edition. Oxford, etc. Elsevier Science Ltd.

Payne, R.E. 1972. Albedo of the sea surface. F. Almos. Sci., 29, 959-970.

Raschke, E., T. H. vonder Haar, M. Pasternak and W. R. Bandeen. 1973. The radiation balance of the Earth atmosphere system from .Nimbus-3 radiation measurements. Washington, DC, National Aeronautics and Space Administration. (NASA-TM-D-7249.)

Scholz, H. and W. Grottenthaler. 1988. Beiträge zum junghalozänen Deglaziationsgeschichte im mittlerem Westgrönland. Polarforschung, 58 1$), 25-40$.
Taylor, R. V. and L. L. Stowe. 1984. Reflectance characteristics of uniform Earth and cloud surfaces derived from Nimbus-7 ERB. $\mathcal{j}$. Geophys. Res., 89 (D4), 4987-4996.

Wal, R.S.W. van de. 1992. Ice and climate. Ph.D. thesis, Utrecht University.

Wal, R. S. W. van de and J. Oerlemans. 1994. An energy balance model for the Greenland ice sheet. Global and Planetary Change, 9 1-2), 115131 .

Wal, R.S. W. van de and 11 others. In press. Mass balance measurements in the Sondre Stromfjord area in the period 1990-1994. Z. Gletcherkd. Glazialgeol.

Warrick, R.A. and J. Oerlemans. 1990. Sea level rise. In Houghton, J. T., G. J. Jenkins and J.J. Ephraums, eds. Climate change: the IPCC scientific assessment. Cambridge, Cambridge University Press, 257-281.

Weidick, A., C. E. Boggild and N. T. Knudsen. 1992. Glacier inventory and atlas of West Greenland. Gronlands Geologiske Undersogelse. Rapport 158.

Williams, R. S., Jr, D. K. Hall and C. S. Benson. 1991. Analysis of glacier facies using satellite techniques. F. Glaciol., 37(125), 120-128.

Zuo, Z. and J. Oerlemans. 1996. Modelling albedo and specific balance of the Greenland ice sheet: calculations for the Sondre Stromfjord transect. F. Glaciol., 42 (141), 305-317. 